\title{
Comparing Heavy Metal Contents of Panax Ginseng Samples from Selected Markets in Tehran and Beijing
}

Parisa Ziarati ${ }^{1 *}$ and Jinous Asgarpanah ${ }^{2}$

${ }^{1}$ Department of Medicinal Chemistry, Pharmaceutical Sciences Branch, Islamic Azad University (IAUPS), Tehran, Iran

${ }^{2}$ Department of Pharmacognosy, Pharmaceutical Sciences Branch, Islamic Azad University (IAUPS), Tehran, Iran

\begin{abstract}
Introduction: Panax Ginseng C. A. Meyer, belonging to the Araliaceae family, is a perennial plant with fleshy roots that grows in Korea and northern China. Panax Ginseng has been regarded as a medicinal plant in traditional oriental medicine. The root of Panax Ginseng is commonly used as herbal medicine. However, little is known about the contents and origin of heavy metals in the samples of herbal plants being sold in local herbal markets in Iran. The objective of the present research was to determine the level of Cadmium, Lead, Zinc, Nickl, Copper and Chromium contents in Panax Ginseng samples purchased from Tehran and Beijing local herbal markets and to find the possible process of contamination.
\end{abstract}

Material and methods: To examine these metal contents in Panax Ginseng, 100 samples from Tehran and 100 samples from Beijing local herbal markets were purchased from 20 and 25 different local herbal markets in Beijin and Tehran respectively in 2012. A certain weight of each sample was determined and then analyzed by atomic absorption spectrophotometer. The concentration levels of heavy metals on the samples were determined as mean \pm SD $(\mathrm{mg} / \mathrm{kg}$ dry weight) of three replicates in each test.

Results: Results showed a significant increase in lead, Cadmium and Chromium contents in Tehran's markets compared to the samples purchased from Beijing markets $(p<0.05)$. Since the amount of heavy metals in the ginseng samples obtained from Iranian markets is much higher than the corresponding figure in the ginseng supplied in the Chinese markets.

Discussion: It may be concluded that the ginseng samples could be contaminated in different stages of transportation and storage. The contamination of medicinal herbs by toxic heavy metals results in serious safety issues due to the increasing popularity of herbal remedies in the world. Therefore, it is critical to analyze heavy metals in herbal medicine in order to assure that the levels of heavy metals do not exceed the required limits established by regulations.

Keywords: Heavy metals; Panax Ginseng; Herbal markets; Tehran; Beijing

\section{Introduction}

Panax Ginseng C. A. Meyer, belonging to the Araliaceae family, is a slow-growing perennial plant with fleshy roots that grows in Korea and northern China. For a long time, Panax Ginseng has been regarded as a medicinal plant in traditional oriental medicine [1,2]. The biological and pharmacological efficacy of this plant has been revealed by modern science. Such healing characteristics of this herb include improving brain function, adaptogenic effects, pain-relieving effects, preventive effects against tumors and anti-tumor activity, enhancing immune system function, anti-diabetic effects, enhancing liver function, adjusting blood pressure, anti-fatigue and anti-stress effects, improving climacteric disorder and sexual functions, as well as anti-oxidative and anti-aging effects [3-6].

The ingredients of ginseng root have been investigated and several classes of compounds have been detected such as triterpene saponins; essential oil-containing polyacetylenes and sesquiterpenes; polysaccharides; peptidoglycans; nitrogen-containing compounds; as well as various ubiquitous compounds such as fatty acids, carbohydrates, and phenolic compounds [7]. Panax Ginseng contains an extraordinarily complex mixture of chemical constituents that can vary with species of the herb, place of origin, and growing conditions. Although different ginseng species may be used slightly differently in traditional medicines, all species contain ginsenosides as active components and most of the pharmacological activity of ginseng can be attributed to these compounds. Ginsenosides are specific types of triterpene saponin, a broad group of chemical compounds. Ginsenosides are found nearly exclusively in Panax species (ginseng) and up to now more than 150 naturally occurring ginsenosides have been detected and extracted from different organs of ginseng [8]. Ginsenosidese appear to be responsible for most of the activities of ginseng including ant carcinogenic, immunomodulatory, antiinflammatory, anti-allergic, anti-atherosclerotic, antihypertensive, and anti-diabetic effects as well as anti-stress activity and effects on the central nervous system [9]. The root of ginseng is a commonly used herbal medicine [10]. However, little is known about the contents and origin of heavy metals in samples of herbal plants being sold in local herbal markets in Iran.

The quality of a crop is determined by the prevailing conditions during growth and can be controlled and tested by the accepted Good Agricultural Practices (GAP). Such controls include seed selection, growth conditions, use of fertilizers, harvesting, drying and storage. In

*Corresponding author: Parisa Ziarati, Department of Medicinal Chemistry, Pharmaceutical Sciences Branch, Islamic Azad University (IAUPS), Tehran, Iran, Tel: 22600037; Fax: 22602059; E-mail: ziarati.p@iaups.ac.ir

Received July 15, 2013; Accepted July 27, 2013; Published July 30, 2013

Citation: Ziarati P, Asgarpanah J (2013) Comparing Heavy Metal Contents of Panax Ginseng Samples from Selected Markets in Tehran and Beijing. J Environ Anal Toxicol 3: 183. doi:10.4172/2161-0525.1000183

Copyright: $\odot 2013$ Ziarati $\mathrm{P}$, et al. This is an open-access article distributed under the terms of the Creative Commons Attribution License, which permits unrestricted use, distribution, and reproduction in any medium, provided the original author and source are credited. 
fact, GAP procedures are, and will be, an internal part of quality control. Apart from these criteria, factors such as the method of extraction, contamination with microorganisms, heavy metals, and pesticides can alter the quality, safety and efficacy of herbal drugs. Using cultivated plants under controlled conditions instead of those collected from the wild can minimize most of these factors $[11,12]$.

By far, the majority of potentially hazardous contaminants and residues are found in the herbs and herbal materials. It has been reported that herbal plants contain significant quantities of some heavy metals, including cadmium, lead and mercury. Exposure to traces of abovementioned heavy metals may affect human health and result in serious illnesses. As a general rule, heavy metal toxicity results in gastrointestinal irritation, renal toxicity and multi-organ toxicity. Thus, the analytical control of metals in plants, especially medicinal plants, is part of quality control. Such controls are to establish their purity, safety and efficacy, as a World Health Organization (WHO) recommended in a number of resolutions. Furthermore, the European Commission has established some standard limits for the lead, cadmium and mercury contents in food supplements that have been in force since March 2001 Commission Regulation [13].

The objectives of the present research were to:

- Determine the level of $\mathrm{Cd}, \mathrm{Pb}, \mathrm{Zn}, \mathrm{Ni}, \mathrm{Cu}$ and chromium in Panax Ginseng samples purchased from Tehran and Beijing local herbal markets.

- Compare the heavy metal contents of Panax Ginseng extracted from the samples bought from local herbal markets in Tehran and Beijing and find the possible contaminating processes.

\section{Materials and Methods}

\section{Sampling description}

To examine the lead, cadmium, copper, chromium, nickel and zinc contents in Panax Ginseng samples, 100 samples were collected from Tehran herbal markets and 100 samples were purchased from 20 and 25 different local herbal markets in Beijin and Tehran respectively in 2012. A certain weight of each samples were digested and then analyzed by atomic absorption spectrophotometer

\section{Estimation of $\mathrm{Cd}, \mathrm{Pb}, \mathrm{Cr}, \mathrm{Cu}, \mathrm{Zn}$ and $\mathrm{Ni}$}

For heavy metal analyses, 5 grams of each sample was weighed and oven-dried at $60^{\circ} \mathrm{C}$ to a constant weight. Each oven-dried sample was put in a mortar until it could pass through a 60 mesh sieve. The samples were stored in clean, dry, high density polyethylene bottles of $100 \mathrm{ml}$ capacity with screw caps. All glassware and plastic containers used in this experiment were washed with liquid soap, rinsed with water, soaked in $10 \%$ volume/volume nitric acid for $24 \mathrm{hrs}$, cleaned thoroughly with distilled water and dried in such a manner to ensure that any contamination does not occur.

One gram of powdered sample was weighed precisely on electronic balance (Shimadzu LIBROR AEX 200G). The samples were put in a $100 \mathrm{ml}$ digestion flask and $5 \mathrm{ml}$ of mixture was added to it and heated on a hot plate in the fuming chamber. A digestion mixture comprising of concentrated HNO3 and hydrochloric acid in the ratio of 6:1 was used for wet digestion of the samples. Blanks and samples were also processed and analyzed simultaneously. All the chemicals used were of analytical grade (AR).

Standardized international protocols were followed for the preparation of material and analysis of heavy metals contents. The flasks were firstly heated slowly and then vigorously till a white residue is obtained. The residue was dissolved and made up to $10 \mathrm{ml}$ with 0.1 $\mathrm{N} \mathrm{HNO} 3$ and $\mathrm{NH}_{4} \mathrm{I}$ solution in a volumetric flask. The samples were analyzed by an Flame Emission Spectrophotometer Model AA-6200 (Shimadzu, Japan) using an air-acetylene flame for heavy metals- $\mathrm{Pb}$, $\mathrm{Cd}, \mathrm{Cr}, \mathrm{Ni}, \mathrm{Zn}$ and $\mathrm{Cu}$. At least two standard solutions were used for each metal. All necessary precautions were taken to avoid any possible contamination of the sample as per the AOAC guidelines [14].

\section{Calibration of equipment}

Standard solutions of heavy metals $(1000 \mathrm{mg} / \mathrm{L})$, namely Copper $(\mathrm{Cu})$, Zinc $(\mathrm{Zn})$, Chromium $(\mathrm{Cr})$, Cadmium $(\mathrm{Cd})$, Lead $(\mathrm{Pb})$ and Nickel $(\mathrm{Ni})$ were procured from the Merck Co. Solutions of varying concentrations were prepared for all the metals by diluting the standards. For the elements under investigation we established the following sensitivity and detection limits respectively of the used FAAS apparatus. $\mathrm{Pb} 0.2$ and $1.0 \mathrm{ppm}, \mathrm{Cr} 0.5$ and $3.0 \mathrm{ppm}, \mathrm{Cd} 0.2$ and $1.0 \mathrm{ppm}$, $\mathrm{Cu} 0.5$ and $3.0 \mathrm{ppm}, \mathrm{Zn} 0.05$ and $5.0 \mathrm{ppm}, \mathrm{Ni} 0.5$ and $4.0 \mathrm{ppm}$.

\section{Statistical analysis}

Values were expressed as the mean $(\mathrm{mg} / \mathrm{kg}) \pm$ standard deviation (SD). The heavy metal contents differences form 2 original country markets were calculated by one way Anova by SPSS 17. Probability values of $<0.05$ were considered significant.

\section{Results}

The concentration levels of heavy metals in the samples were determined as mean \pm SD of three replicates in each test and determined based on sample dry weight shows in Table 1 for Iranian and Chinese samples.

Results showed a significant increase in the lead, cadmium and chromium contents $(\mathrm{p}<0.05)$ in the samples bought from Tehran's markets compared to that of samples were purchased from Beijing markets. This discrepancy of concentration might be the result of transportation process. In Figure 1 comparing Heavy Metal contents in ginseng samples purchased from selected local herbal markets in Tehran and Beijing in 2012 can be seen.

\section{Lead}

Lead $(\mathrm{Pb})$ is the main source of concern in terms of heavy metals contamination of Panax Ginseng samples obtained from herbal market

\begin{tabular}{|c|c|c|c|c|}
\hline Metal & Location & Range $(\mathrm{mg} / \mathrm{kg} \mathrm{DW} \pm \mathrm{SD})$ & $\begin{array}{l}\text { Mean content } \\
(\mathrm{mg} / \mathrm{kg} \mathrm{DW} \pm \mathrm{SD})\end{array}$ & $\begin{array}{l}\text { WHO } \\
\text { Permissible } \\
\text { level }\end{array}$ \\
\hline \multirow{2}{*}{$\mathrm{Pb}$} & Tehran & $29.91 \pm 0.02-33.46 \pm 0.04$ & $31.21 \pm 0.04$ & \multirow{2}{*}{10} \\
\hline & Beijing & $14.81 \pm 0.05-25.11 \pm 0.03$ & $16.21 \pm 0.04$ & \\
\hline \multirow{2}{*}{$\mathrm{Cd}$} & Tehran & $4.87 \pm 0.05-11.37 \pm 0.02$ & $9.67 \pm 0.03$ & \multirow{2}{*}{0.3} \\
\hline & Beijing & $1.28 \pm 0.03-4.82 \pm 0.03$ & $2.77 \pm 0.03$ & \\
\hline \multirow{2}{*}{$\mathrm{Ni}$} & Tehran & $15.77 \pm 0.07-25.66 \pm 0.03$ & $22.96 \pm 0.12$ & \multirow{2}{*}{--} \\
\hline & Beijing & $22.11 \pm 0.04-31.71 \pm 0.03$ & $25.16 \pm 0.03$ & \\
\hline \multirow{2}{*}{$\mathrm{Zn}$} & Tehran & $36.19 \pm 0.17-44.22 \pm 0.11$ & $41.79 \pm 0.15$ & \multirow{2}{*}{100} \\
\hline & Beijing & $33.17 \pm 0.13-40.19 \pm 0.16$ & $37.12 \pm 0.15$ & \\
\hline \multirow{2}{*}{$\mathrm{Cr}$} & Tehran & $29.47 \pm 0.04-36.72 \pm 0.07$ & $34.26 \pm 0.05$ & \multirow{2}{*}{2} \\
\hline & Beijing & $8.98 \pm 0.04-8.98 \pm 0.04$ & $37.12 \pm 0.15$ & \\
\hline \multirow{2}{*}{$\mathrm{Cu}$} & Tehran & $5.44 \pm 0.05-11.27 \pm 0.06$ & $8.11 \pm 0.06$ & \multirow{2}{*}{100} \\
\hline & Beijing & $40.19 \pm 0.16-10.17 \pm 0.05$ & $7.39 \pm 0.04$ & \\
\hline
\end{tabular}

Table 1: Average and minimum and maximum of metals $(\mathrm{mg} / \mathrm{kg} \mathrm{DW} \pm \mathrm{SD}$ ) in Panax Ginseng samples purchased from Tehran and Beijing local herbal markets in 2012. 


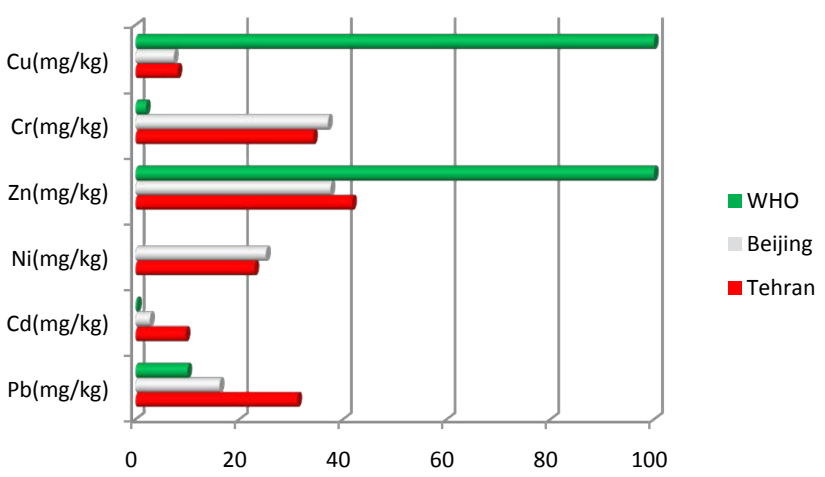

Figure 1: Heavy metal contents (mg/kg DW) in Panax Ginseng samples purchased from selected local herbal markets in Tehran and Beijing in 2012.

in Tehran and Beijing. Lead concentration of the Iranian samples ranged from $29.91 \pm 0.02 \mathrm{mg} / \mathrm{kg}$ to $33.46 \pm 0.04 \mathrm{mg} / \mathrm{kg}$ and lead concentration of the Chinese samples ranged from $14.81 \pm 0.05 \mathrm{mg} / \mathrm{kg}$ to $25.11 \pm 0.03 \mathrm{mg} / \mathrm{kg}$. Quality control of $100 \%$ of 180 samples showed that both group of samples purchased from Tehran and Beijing markets contained $\mathrm{Pb}$ concentrations that exceeded the permissible limit set by WHO (WHO, 1989) [15]. Prescribed limit for Pb contents in herbal medicine is $10 \mathrm{mg} / \mathrm{kg}$ dry weight while the dietary intake limit for $\mathrm{Pb}$ is $3 \mathrm{mg} /$ week. Lead is known to cause neurological disorders, anemia, kidney damage, miscarriage, lower sperm count and hepatotoxicity in higher concentration ATSDR [16].

\section{Cadmium}

Cadmium (Cd) is another major source of concern in terms of heavy metals contamination of ginseng samples. Cadmium concentration of the Iranian samples ranged from $4.87 \pm 0.05 \mathrm{mg} / \mathrm{kg}$ to $11.37 \pm 0.02 \mathrm{mg} / \mathrm{kg}$ and Cadmium concentration of Chinese samples ranged from $1.28 \pm 0.03 \mathrm{mg} / \mathrm{kg}$ to $4.82 \pm 0.03 \mathrm{mg} / \mathrm{kg}$. Quality control of $100 \%$ of 180 samples showed that both group of samples showed that cadmium concentrations exceeded the permissible limit set by the European Commission Regulation [13]. WHO prescribed limit for $\mathrm{Cd}$ contents in medicinal plant at $0.3 \mathrm{mg} / \mathrm{kg}$ [15] and the maximum acceptable concentration for food stuff is around $1 \mathrm{ppm}$ [17]. Cadmium intoxication can lead to kidney, bone and pulmonary damages [18].

\section{Chromium}

The mean concentration of $\mathrm{Cr}$ (Table 1) found in different Iranian samples was $31.21 \mathrm{mg} / \mathrm{kg}$ DW and Cr contents ranged from $8.98 \pm 0.04$ $\mathrm{mg} / \mathrm{kg}$ to $15.36 \pm 0.07 \mathrm{mg} / \mathrm{kg}$ in Chinese samples. Both group samples contained higher amounts of chromium than permissible limit of $0.5 \mathrm{ppm}$ set by FDA [19]. However, WHO is yet to set limits for $\mathrm{Cr}$ contents in medicinal plants. However, Canadian authorities have set limits of $\mathrm{Cr}$ contents in raw medicinal plant material at $2 \mathrm{mg} / \mathrm{kg}$ [20]. It is notable that higher concentration of $\mathrm{Cr}$ than the critical level of 5.30 $\mathrm{ppm}$ could be a probable cause for yields reduction. The toxic impacts of $\mathrm{Cr}$ intake by human beings are known as skin rash, nose irritations, bleedings, upset stomach, kidney and liver damage, nasal itch and lungs cancer. Chromium deficiency is, moreover, characterized by disturbance in glucose lipids and protein metabolism [21].

\section{Discussion}

Concentration of essential and non-essential heavy metals in medicinal plants beyond permissible limit is a matter of great concern to public safety worldwide. The problem is rather serious in Iran because medicinal plants are neither controlled nor properly regulated by quality assurance parameters. In order to find contaminating agents in Panax Ginseng (A herbal plant) and determining different steps of the pertinent contamination process, a comparison was carried out between the Panax Ginseng supplied in the Tehran (Iran) local markets and the crop available in local markets of Beijing (China) as the sole exporter of the herb to Iran.

A comparison between acceptable global standards and the level of $\mathrm{Cr}, \mathrm{Cd}$ and $\mathrm{Pb}$ found in Panax Ginseng showed that the majority of the samples of medicinal plants (Panax Ginseng roots) obtained from Tehran markets contained higher levels of such heavy metals. Since the amount of heavy metals in the Panax Ginseng samples taken from Iranian markets is much higher than the corresponding content levels in the Panax Ginseng supplied in the Chinese markets, it may be concluded that the crop is contaminated in different stages of transportation and storage.

The results suggest that such organizations as the Health Ministry should assist in this regard by carrying out premarket reviews of all imported medicinal-herbal plants and herbal drugs before their launch. The products available in the markets should be analyzed regularly to ensure that they are free of hazardous ingredients and that the products actually contain the ingredients indicated on the labels. It is recommended considerable attention should be paid to alternative therapies, especially for the patients who may intake such herbal medicines for a long time. Therefore, certain group of patients such as elderly with cardiovascular problems and kidney deficiency who may intake these herbal products for long term should be extra cautions as they are more susceptible to toxicities.

\section{Acknowledgment}

This work was supported by the Pharmaceutical Sciences Branch, Islamic Azad University, Tehran, I. R. Iran

\section{References}

1. Kee CH (1999) the Pharmacology of Chinese Herbs Herbs with Multiple Actions - Ginseng, CRC Press, New York, USA.

2. Yun TK (2001) Brief introduction of Panax ginseng C.A. Meyer. J Korean Med Sci 16: S3-5.

3. Nocerino E, Amato M, Izzo AA (2000) The aphrodisiac and adaptogenic properties of ginseng. Fitoterapia 71 Suppl 1: S1-5.

4. Choi KT (2008) Botanical characteristics, pharmacological effects and medicinal components of Korean Panax ginseng CA. Meyer. Acta Pharmacologica Sinica 29: $1109-1118$.

5. Jia L, Zhao $Y$ (2009) Current evaluation of the millennium phytomedicineginseng (I): etymology, pharmacognosy, phytochemistry, market and regulations. Curr Med Chem 16: 2475-2484.

6. Jia L, Zhao Y, Liang XJ (2009) Current evaluation of the millennium phytomedicine-ginseng (II): Collected chemical entities, modern pharmacology, and clinical applications emanated from traditional Chinese medicine. Curr Med Chem 16: 2924-2942.

7. Tang W, Eisenbrand G (1992) Chinese Drugs of Plant Origin. Springer-Verlag, Berlin 711-737.

8. Christensen LP, Steve LT (2009) Ginsenosides: Chemistry, Biosynthesis, Analysis, and Potential Health Effects. Academic Press 55: 1-99.

9. Lu JM, Yao Q, Chen C (2009) Ginseng compounds: an update on their molecular mechanisms and medical applications. Curr Vasc Pharmacol 7: 293302.

10. Lee SY, Kim YK, Park Nam II, Kim CS, Lee CY, et al. (2010) Chemical constituents and biological activities of the berry of Panax ginseng. $\mathrm{J}$ Med Plants Res 4: 349-353.

11. Eskinazi D, Blumenthal M, Farnsworth N, Riggins CW (1999) Botanica 
Citation: Ziarati P, Asgarpanah J (2013) Comparing Heavy Metal Contents of Panax Ginseng Samples from Selected Markets in Tehran and Beijing. J Environ Anal Toxicol 3: 183. doi:10.4172/2161-0525.1000183

Page 4 of 4

Medicine: Efficacy, Quality, Assurance, and Regulation. Mary Ann Liebert, New York, USA.

12. Li F, Sun S, Wang J, Wang D (1998) Biomed Chromatogr 12-78.

13. Commission Regulation (EC) (2001) setting maximum levels for certain contaminants in foodstuffs. Official Journal of the European Communities No. $466 / 2001$.

14. AOAC (Association of Official Analytical Chemists) (1998) Wet digestion for non-volatile metals in: AOAC official methods of analysis.

15. WHO (1989) Evaluation of Certain Food Additives and Contaminants. WHO Technical Report Series 776, Geneva: World Health Organization.
16. ATSDR (2007) Toxicological Profile for Lead. Agency for Toxic Substances and Disease Registry: U.S. Department of Health and Human services, Public Health Service, Atlanta, GA, United States.

17. Neil PO (1993) Minor Element and Environmental Problems. Envir Chem.

18. Godt J, Scheidig F, Siestrup CG, (2006) The Toxicity of Cadmium and resulting hazards for human health. J Occup Toxicol Med 22: 1-6.

19. FDA (1999) (U.S. Food and Drug Administration). U.S. Department of Health and Human Services, 21 CFR 556: 60.

20. WHO (2005) Quality Control Methods for Medicinal Plant Materials. Geneva.

21. McGrath SP, Smith S (1990) Chromium and Nickel in heavy metals in soils. In: B. J. Alloway (1990) Blackie, Glasgow 125. 